\title{
0 trabalho de campo em Medicina Tropical: objetivos, planejamento e aspectos operacionais
}

\author{
Field work in Tropical Medicine: objectives, \\ planning and operational aspects
}

\begin{abstract}
João Barberino Santos ${ }^{1}$
Resumo O trabalho de campo é de fundamental importância ao conhecimento das chamadas doenças tropicais. Ele permite estabelecer com mais precisão a prevalência das doenças endêmicas e de suas conseqüências sócio-econômicas; propicia o estudo das diversas variantes clínicas das enfermidades, dos fatores epidemiológicos desencadeantes e mantenedores de determinada condição mórbida no ambiente do campo onde ocorrem, proporcionando a investigação do agente etiológico, dos diversos reservatórios e vetores nas condições naturais de transmissão. Este artigo aborda objetivos e questões relevantes de ordem estrutural, logística e operacional no desempenho deste tipo de investigação.
\end{abstract}

Palavras-chaves: Doenças tropicais. Trabalho de campo. Ensaio clínico. Epidemiologia.

Abstract Field work is of fundamental importance for information regarding so-called tropical diseases. It enables more precise establishment of the prevalence of endemic diseases and of its social and economic consequences, allows study of the many clinical variants of diseases, of the epidemiological factors which trigger and maintain a certain morbid condition in the field environment where it occurs, thus enabling the investigation of the causal agent, of the diverse reservoirs and vectors in the natural conditions of transmission. This article approaches relevant structural, logistic and operational objectives and aspects in the performance of this type of investigation.

Key-words: Tropical diseases. Field assays. Clinical trials. Epidemiology.

A Medicina Tropical compreende particularmente as doenças infecciosas e parasitárias cuja incidência é maior nas áreas tropicais e sua transmissão é facilitada pelas baixas condições sócio-econômicas. Desta forma, as enfermidades ditas tropicais incidem sobremaneira na área rural, onde ao lado do pauperismo e da precariedade de saneamento, proliferam os agentes, os vetores e os reservatórios dependentes dos respectivos ecossistemas. Podem ocorrer, ainda, em áreas urbanas, particularmente nos últimos anos, com o intenso fluxo populacional rural-urbano.

Em verdade, o hospital continua sendo o lugar mais adequado para se estudar o doente mas, em Medicina Tropical, o campo reunindo os elementos desencadeadores e mantenedores da doença, permite estudá-la e compreendê-la em todos os seus determinantes e variantes. O trabalho de campo é, portanto, aquele que é desenvolvido no âmbito da zona rural, podendo ou não ser complementado com experiências ou procedimentos laboratoriais realizados em centros urbanos, graças aos novos avanços tecnológicos que permitem a coleta e o transporte de material biológico a longas distâncias, em condições de processá-lo e examiná-lo.

Segundo Samuel Pessoa ${ }^{23}$, enquanto não for fixado no Brasil um critério uniforme para o estabelecimento do que seja zona rural, deve ser adotado o conceito internacional que considera como rural a população de todo distrito cujo núcleo tiver número total de habitantes inferior a certo limite (entre nós, de 2000 a 3000) e cuja população agrícola formar uma percentagem superior a $60 \%$ da população ativa total.

A investigação de campo, embora realizada longe dos grandes centros de pesquisa, não deixa de ter grande valor para o conhecimento das doenças tropicais, principalmente em seus aspectos clínicos e epidemiológicos. Com efeito, foi o esforço sob as limitadas condições do interior de Lassance, em Minas

\footnotetext{
1. Núcleo de Medicina Tropical da Universidade de Brasília, Brasília, DF.

Endereço para correspondência: Dr. João Barberino Santos. Núcleo de Medicina Tropical/UNB, Campus Universitário, Asa Norte, Caixa Postal 4517, 70919-970 Brasília, DF, Brasil.

Tel: 5561 273-5008; Fax:55 61 273-2811

e-mail: tropical@unb.br

Recebido para publicação em 17/6/2001.
} 
Gerais, que permitiu a Carlos Chagas, nosso maior gênio científico, descobrir a moléstia que tem o seu nome, esclarecendo o agente etiológico, o inseto transmissor, os animais sensíveis, o doente humano e os reservatórios do protozoário causador da enfermidade ${ }^{8}$.

\section{OBJETIVOS DO TRABALHO DE CAMPO}

Várias são as finalidades que determinam o trabalho de campo em Medicina Tropical:

Existência, incidência e prevalência da doença. $A$ pesquisa de campo serve para comprovar a existência de uma doença em uma determinada localidade, mesmo nas mais distantes e inóspitas regiões. Foram observações conduzidas nas selvas de Roraima que confirmaram a existência de oncocercose ao Norte do Brasil, entre a tribo lanomama, partindo-se do conhecimento que se tinha desta filariose na Amazônia Venezuelana e da característica nômade destes índios ${ }^{18}$.

A verdadeira incidência de muitas doenças tropicais, como por exemplo, da febre amarela silvestre, só pode ser determinada através dos inquéritos de campo, onde é possível avaliar-se a incidência de todas as formas clínicas $^{28}$. Também, os fatores de risco de contrair uma doença pela população podem ser levantados e estudados na área onde ocorre. Correlacionando as áreas de incidência de pênfigo foliáceo, em Goiás, com a presença de simulídeos, Auad $^{3}$ confirmou os achados sobre um possível papel destes artrópodos na transmissão da moléstia.

Da mesma forma, a prevalência mais precisa das doenças tropicais é estabelecida pelo trabalho de campo. Assim, a prevalência de infecção malárica em uma determinada área, é comprovada pela busca ativa da infecção através do exame de sangue sistemático da população ${ }^{4}$.

Determinação das formas clínicas, da evolução e prognóstico. As doenças observadas no hospital, constituem amostra viciada, composta de casos multissintomáticos com quadro clínico estabelecido, geralmente em fase de gravidade. Raras vezes, a depender da finalidade do hospital, da área de influência a que se destina, ou do interesse do corpo clínico, doentes oligossintomáticos, ou mesmo assintomáticos, são atendidos nos centros de saúde. Por conseguinte, a freqüência dos casos assintomáticos de uma doença somente será conhecida através da busca ativa conduzida na área de ocorrência ${ }^{26}$. Igualmente, a caracterização da forma aguda, da forma aguda inaparente e da forma indeterminada da doença de Chagas é feita rotineiramente nos estudos de campo ${ }^{16}$.

Além disso, os estudos longitudinais de campo podem esclarecer os caminhos de evolução, ou de involução, espontâneos ou não, das diferentes formas clínicas e, através do conhecimento do potencial evolutivo, possibilitar o estabelecimento do prognóstico. O acompanhamento metódico de pacientes em área endêmica de esquistossomose demonstrou de modo convincente a involução da forma hepatoesplenica da parasitose, após o tratamento específico ${ }^{6}$.
Morbidade, letalidade e conseqüências sócioeconômicas. A pesquisa de campo concorre para o conhecimento das conseqüências biológicas, médicas e sociais da doença sobre o indivíduo, favorecendo o melhor planejamento das medidas de controle. Permite, também, o levantamento e a avaliação dos fatores de morbidade e de risco letal, através da investigação habitacional e ambiental, hábitos de vida, mecanismos de transmissão, fatores genéticos e nutricionais, coparticipação de infecções intercorrentes, efeitos medicamentosos e imunossupressores, assim como o papel da parasitemia do agente etiológico ${ }^{7}$.

Corolário destes elementos, as conseqüências sócio-econômicas do processo patológico sobre o indivíduo e/ou sobre a comunidade resultam fundamentalmente de três determinantes principais: a mortalidade, a morbidade e a incapacidade laborativa, avaliados com mais veracidade no próprio ambiente onde a doença ocorre. No campo, podem ser estudados os efeitos patológicos sobre a escolaridade, sobre a atenção, a memória, a inteligência e demais funções mentais, faltas a escola e ao trabalho, a repercussão da doença na comunidade, os resultados sociais do desemprego, da aposentadoria precoce, das perdas econômicas e do custo da doença. Assim, as notórias conseqüências sociais e econômicas que o Mal de Hansen acarreta para a vida em sociedade só podem ser aquilatadas com exatidão na observação de todos os elementos da convivência do hanseniano ${ }^{19}$.

Variações regionais. Através de estudos realizados no campo se pode estabelecer as variações regionais da doenças tropicais em seus diferentes aspectos, tais como: espécies e cepas do agente, vetores, reservatórios, mecanismos de transmissão, variações do quadro e da intensidade clínica, etc. Por exemplo, estudo desenvolvido na região do Alto Purus, na Amazônia, mostrou o caráter clínico peculiar e a gravidade letal da chamada hepatite de Lábrea, diferenciando-a da hepatite infecciosa clássica pelo vírus $\mathrm{B}^{28}$.

Dinâmica da transmissão. As modificações exercidas pelo homem sobre a dinâmica da transmissão, afetando os principais elementos da história natural das doenças tropicais - parasitos, vetores e reservatórios são também objeto das pesquisas de campo. Avaliase, por exemplo, as alterações provocadas pelos inseticidas sobre os hábitos dos vetores, os determinantes da domesticação de vetores, a extinção e substituição de vetores e de reservatórios naturais, as modificações do comportamento ecológico dos parasitos etc. Trabalhos conduzidos no interior de Goiás registraram a domiciliação progressiva do $R$. neglectus 
em substituição ao T. infestans, como vetor da doença de Chagas neste estado ${ }^{31}$.

Os estudos de campo sobre a transmissão congênita e lesões placentárias causadas pelas doenças infectoparasitárias também são possíveis através do acompanhamento de gestantes, da investigação em recém-nascidos de mães doentes e do exame de placentas coletadas após o parto².

Profilaxia e terapêutica. As medidas profiláticas e de controle das doenças tropicais carecem da comprovação de sua eficácia nas áreas onde elas ocorrem. Nem sempre o êxito no laboratório corresponde a uma efetividade na prática, motivado pelas circunstâncias locais. Um produto químico que logrou uma ação inseticida eficaz sobre uma determinada espécie vetorial no laboratório pode, contrariamente, não funcionar no campo como medida de proteção. É ilustrativo a demonstração na Amazônia Ocidental Brasileira, da reduzida eficácia e dos efeitos colaterais da aplicação da vacina antimalárica sintética SPf66, em área de transmissão ${ }^{32}$.

\section{PLANEJAMENTO DO TRABALHO DE CAMPO}

Organização do projeto. O projeto deve ser descrito com todos os possíveis detalhes, com orçamento completo e cronograma, atentando para os aspectos sociais e climáticos na área rural do estudo. Freqüentemente, nos períodos de chuva, as estradas tornam-se intransitáveis no campo, impossibilitando os deslocamentos e inviabilizando o desenvolvimento da pesquisa. Ademais, costumes e hábitos sociais da população durante comemorações, feriados e dias santos deverão ser respeitados.

Necessariamente, o projeto deverá ser submetido e receber aprovação de um comitê de ética. O estudo em seres humanos deve garantir a voluntariedade, a confidencialidade, com danos mínimos aos participantes ${ }^{17}$. A Organização Mundial de Saúde resume em três princípios éticos básicos que é preciso observar em toda investigação que inclua seres humanos: a justiça, o respeito pelas pessoas e o caráter benéfico (que consiste em aumentar ao máximo os benefícios e minimizar os prejuízos) ou não maléfico (não causar danos) ${ }^{21}$.

Os participantes, ou os seus responsáveis, deverão assinar um termo de consentimento informado que é a confirmação voluntária por parte do indivíduo de sua concordância em participar de um determinado ensaio clínico e representa a documentação da mesma. O consentimento será solicitado após haverem sido devidamente informados sobre os objetivos, procedimentos, possíveis benefícios e potenciais riscos para os participantes e para a comunidade; sobre a liberdade de permanecer ou sair do estudo a qualquer momento sem que isso venha prejudicar a assistência médica que possa receber; e, enfim, sobre seus direitos e responsabilidades assegurados na Declaração de Helsinqui ${ }^{21}$.
Analogamente, ensaios terapêuticos são realizados para certificar-se da eficácia, efeitos e reações colaterais de um medicamento no tratamento em massa contra doenças endêmicas. Investigações concluídas em uma comunidade no estado de Rondônia, contribuíram para confirmar a vantagem da mefloquina no tratamento da malária falciparum no Brasil ${ }^{30}$.

Estudos anátomo-patológicos. No campo podem ser realizadas biópsias de pacientes com formas clínicas atenuadas que rotineiramente não são atendidos no hospital. Determinadas patologias regionais de curso rápido e que ocorrem em espaços geográficos delimitados, como hepatites infecciosas e febres hemorrágicas, exigem que biópsias, necrópsias e viscerotomias para estudos anátomo-patológicos sejam realizadas no próprio local de ocorrência da doença1. Eventualmente, as viscerotomias e necrópsias deverão ser estendidas aos animais silvestres, doentes ou mortos, quando as epidemias sucederem concomitantes às epizootias ${ }^{25}$.

No campo, os estudos experimentais podem ser classificados em controlados e não controlados. Os controlados exigem a tomada de dados básicos e a utilização de uma área de comparação; por exemplo, quando no ensaio com mosquiteiros impregnados com inseticida em uma comunidade, utiliza-se paralelamente uma outra população em uso de mosquiteiros não impregnados como controle ${ }^{29}$. Os não controlados são feitos sem controle inicial ou paralelo; exemplifica esse tipo de estudo a aplicação sistemática de inseticida com objetivo de reduzir ou exterminar populações de triatomíneos quando não se tomam dados básicos iniciais ou não se mantém áreas de comparação ou testemunha, mas avaliações feitas periodicamente.

Escolha das áreas teste e testemunha. A escolha da área teste não poderá ser ditada pelas comodidades oferecidas à execução do trabalho nem, tampouco, por quaisquer conveniências particulares. No campo, não se poderá exigir as facilidades de acomodação que se tem nas cidades mas, antes, estar-se-á determinado a aceitar uma cota de renúncia ao conforto e de sacrifícios pessoais. Será inútil cruzar os braços e reclamar da ausência ou da precariedade dos meios; é mister de quem se dispõe a pesquisar no campo criar as condições mínimas para a execução dos objetivos propostos. Providenciará o alojamento da equipe e a unidade local de centralização das tarefas técnicas e de laboratório, buscando os recursos disponíveis para instalação e continuidade das funções, organizando o ambiente propício para a melhor conservação dos aparelhos e instrumentos de trabalho.

Em geral, três premissas se fazem particularmente importantes como critérios para escolha de uma área de campo. Em primeiro lugar, deverá ter comprovada 
alta prevalência da doença que se pretende estudar. Samuel Pessoa insiste em uma recomendação dos chineses de que as pesquisas de campo sobre doenças parasitárias devem ser feitas onde elas reinam endemicamente ${ }^{22}$. Em seguida, é necessário que tenha um tamanho suficiente que permita se tirar conclusões verdadeiras, porém realístico e limitado à capacidade de atendimento do pesquisador, requisito importante levando-se em consideração a rarefação da densidade demográfica rural. Enfim, deverá estar relativamente isolada e ter uma população estável do ponto de vista migratório, permitindo melhor conhecê-la, mantê-la sob controle e sem descontinuidade das observações pertinentes a serem feitas, principalmente nos estudos longitudinais de longa duração.

Por vezes, do hospital pode partir o indício para a investigação a ser realizada no campo. Assim, o aumento inusitado da freqüência de atendimento de pacientes portadores de uma enfermidade, procedentes de uma determinada região, poderá indicar a necessidade da investigação epidemiológica onde 0 surto esteja ocorrendo ${ }^{10}$.

A área testemunha deverá ser comparável à área teste em seus vários aspectos, inclusive aspectos sanitários e sócio-econômicos, e guardar coerência com os aspectos metodológicos exigidos pela investigação. Por exemplo, a avaliação de um inseticida no controle de uma população de anofelinos, exigirá uma área testemunha fora do alcance de vôo destes vetores, capaz de excluir o viés do efeito diversivo sobre os mosquitos, provocado pela ação repelente do produto químico ${ }^{5}$.

Participação comunitária. É fundamental para o êxito da pesquisa de campo, uma visita prévia à área para primeiros contatos e atividades preliminares. Antes de tudo, o pesquisador irá conhecer e escutar a população sobre os seus problemas e anseios, levando em consideração a cultura local, respeitando o saber popular e concentrando atenção às informações recebidas, suscitando a mobilização em torno de interesses concretos da coletividade. Essa exigência garante estabelecer o vínculo de confiança e a aceitação da comunidade e, ao mesmo tempo, verificar a receptividade da intervenção. Só então, irá explicar as finalidades do estudo aos líderes e agentes comunitários e aos futuros participantes. Um censo e um inquérito sumário iniciais servirão para travar conhecimento das dificuldades existentes e avaliar a exeqüibilidade da pesquisa. Nesta oportunidade, serão relacionadas as facilidades e os possíveis apoios percebidos; um mapeamento completo da área será efetuado e, se necessário, a numeração individual das moradias, que permitam futuro reconhecimento geográfico dos locais de ação.

O trabalho de campo poderá resultar em insucesso se não tiver a plena compreensão e colaboração da comunidade. Terá ainda mais chance de êxito se conseguir uma participação ativa da população alvo.
Atitudes de ameaça e de chantagem, além de antiéticas e condenadas, nada permitirá ser conseguido porque a participação será tanto mais efetiva quanto mais espontânea e convencida dos reais benefícios que advirão com os estudos. A participação comunitária voluntária é um dos elementos essenciais não só ao êxito das pesquisas de campo que inclua o estudo da população, mas também, exercida ativa, consciente e permanente, é fundamental ao controle das endemias, particularmente em termos de prevenção e nos seus estágios de consolidação e vigilância ${ }^{11}$.

A motivação e a mobilização comunitárias no campo não apenas são facilitadas, mas muitas vezes estará na dependência da adesão dos líderes da comunidade, dos professores e dos agentes de saúde, pela estreita relação de aceitação e confiança que detém junto à população. O envolvimento das lideranças comunitárias do povoado rural de Cansanção, Minas Gerais, revelouse de valor capital na manutenção de um projeto de controle da doença de Chagas, automaticamente funcionante durante dez anos, com evidentes resultados na interrupção da transmissão vetorial da tripanosomíase ${ }^{12}$.

Participação de centros de pesquisa e de órgãos governamentais. As universidades e centros de pesquisa participam dos trabalhos de campo fornecendo orientação e apoio técnico e, o seu papel não deverá ter apenas a finalidade da publicação e difusão do conhecimento mas, também, de reverter o resultado da pesquisa em real benefício para a comunidade.

O pesquisador será cauteloso quanto à participação de empresas privadas e deverá recusar, sob qualquer pretexto, inclusive de privilégios pessoais, qualquer tipo de interferência na exatidão e veracidade dos resultados obtidos.

Os órgãos governamentais, através das Secretarias de Saúde e das Prefeituras Municipais colaboram com as pesquisas de campo através de ajuda financeira e de apoio logístico. Mesmo as Prefeituras de municípios dotados de poucos recursos podem emprestar uma colaboração muito importante, por ser local e imediata. Aqui, do mesmo modo, o pesquisador não deverá permitir a ingerência ou qualquer conotação política em seu mister.

Participação de médicos e hospitais locais. $O$ pesquisador, porque provém de uma universidade ou de um centro de pesquisa, não deverá investir-se de vaidades e de arrogância frente aos médicos e a outros profissionais já atuantes na área mas, em vez disso, tratará de tê-los como aliados de sua causa. No campo, os diplomas, títulos e conhecimentos do pesquisador freqüentemente pouco, ou mesmo, de nada valem para resolver problemas e enfrentar as mais diversas e adversas situações inerentes ao ambiente rural. A cooperação técnica com os profissionais de saúde cria interesse e entusiasmo, e favorece a troca de informações preciosas. O investigador não poderá absolutamente atuar isolado no campo, onde não faltam 
problemas e carências de toda espécie, sob pena de não conseguir atingir os seus objetivos.

É de interesse que se mantenha os médicos informados sobre o andamento e resultados já conseguidos na pesquisa e, ao término da investigação, Ihes repasse as conclusões finais e uma cópia do trabalho publicado. Geralmente, médicos e hospitais locais condicionam ao cumprimento integral deste item, a garantia de colaboração.

O trabalho de campo dependerá, enfim, da cooperação de todos aqueles envolvidos na tarefa de conservação da saúde: paramédicos, agentes de saúde, farmacêuticos e práticos de farmácia, odontólogos e protéticos, auxiliares de enfermagem e, em certas sociedades, até mesmo de curandeiros, os quais poderão fornecer informações importantes e propiciar uma comunicação mais eficiente com os membros da comunidade.

A equipe de pesquisa pode favorecer o bom relacionamento com os profissionais de saúde atuantes no campo facilitando-Ihes o acesso e a aquisição de livros e periódicos, organizando debates e reuniões científicas na área, proporcionando a oportunidade de freqüentarem cursos de reciclagem nos grandes centros, nas universidades ou nas instituições de onde procedem.

Participação de religiosos e de militares. No trabalho de campo, a colaboração de religiosos e de militares, em algumas circunstâncias, é de suma importância. A adesão do apoio de religiosos, como ocorre com os missionários que atuam na Amazônia, reforça a confiança da população no trabalho da pesquisa e aumenta a participação da comunidade.

Os militares poderão garantir a segurança da equipe em determinadas áreas de conflito ou de algum tipo de tensão, como acontece nas áreas de fronteira. Do mesmo modo, a compreensão e o apoio dos delegados de polícia tem esse efeito benéfico protetor sobre a equipe de pesquisa.

Formação da equipe de trabalho. Um trabalho de campo poderá envolver a participação de especialistas em várias áreas, como Estatística, Epidemiologia, Parasitologia, Entomologia, Imunologia, etc., além da Clínica. Mas, não há necessidade da presença de todas essas pessoas no campo. A composição e o tamanho da equipe dependerá da dimensão do ensaio e da instituição a que está filiado ${ }^{13}$.

Com freqüência, muito pessoal especializado na equipe leva às disputas de gerenciamento e criação de um clima desfavorável à produção científica. Samuel Pessoa chama à atenção para o perigo crescente da maléfica tendência de hipertrofia do pessoal de chefia nas equipes de pesquisa, principalmente na investigação de campo que exige, ao contrário, numeroso pessoal técnico e subalterno. Cita, como exemplo, o estudo sobre o valor de um inseticida, que implicará na necessidade da mobilização de vários técnicos, entomologistas, biologistas, rociadores, serventes, etc ${ }^{24}$.
A equipe será conduzida por um coordenador de campo responsável pelo desenvolvimento da investigação nos seus aspectos operacionais e que atuará como elemento chave do ensaio no dia-a-dia ${ }^{13}$. O coordenador é a pessoa responsável pelo ensaio clínico, pelos direitos, saúde e bem estar das pessoas que participam do ensaio; tem a responsabilidade geral de assegurar a plenitude e a exatidão do processo de coleta dos dados ${ }^{21}$. O coordenador de campo deve aliar ao conhecimento técnico, as qualidades pessoais de liderança para garantir a qualidade dos dados coletados e o sucesso da investigação ${ }^{20}$.

Uma equipe de trabalho de campo deverá estar solidária e bem entrosada entre si, possuir senso comum e pensamento aberto, ter um bom conhecimento da área de estudo, agir estritamente em conformidade com os princípios da ética, desenvolver a boa convivência capaz de estabelecer uma relação de confiança e de empatia com a população e, enfim, ser movida pela real dedicação, interesse e responsabilidade pelo que faz.

Planejamento do trabalho. O planejamento do trabalho será flexível, não estático, aberto a modificações e a adaptações imprevistas, geradas no decorrer da pesquisa. Proporcionará a vigilância constante e espaço para a observação de novos aspectos, de evidências e situações especiais surgidas e não previstas no plano original da investigação. O plano de trabalho incluirá previsão de substituições das desistências ou abandono das pessoas do estudo, migrações de participantes da área de estudo, e casos de óbito.

Dever-se-á optar pelas técnicas simples de coleta de material biológico adequadas para o campo e ao uso de equipamento preferentemente descartável ou de fácil conservação no ambiente rural.

A pobreza e o isolamento das áreas de campo, em geral com longas distâncias aos centros de abastecimento, exigirá do pesquisador uma previsão realista do material de consumo necessário à continuidade da pesquisa, sob pena de sofrer interrupções imprevistas e indesejadas com prejuízo para os resultados finais.

Os dados deverão ser coletados em uma ficha précodificada para facilitar a apuração. Aliás, hoje em dia, usa-se cada vez mais os modernos e práticos aparelhos portáteis de microcomputação para este fim. A ficha, além de simples e prática para facilitar o rápido preenchimento, deverá ser submetida a um pré-teste adequado.

Protocolos longos são mais apropriados para hospitais ou centros de pesquisa, mas são pouco práticos para o trabalho de campo.

Amostragem e critérios diagnósticos. Quando a população é numerosa, a amostra estatística diminui o custo e o tempo de trabalho, e leva a conclusões verdadeiras, desde que seja determinada adequadamente em relação à população geral. 
Amostras de uma pequena fração estará sujeita a erros quando as conclusões forem extrapoladas à população total; por outro lado, quanto maior for, estará sujeita a erros de mensuração. No entanto, a amostra poderá ser contra-indicada em situações em que o procedimento preferível é o estudo de todo o grupo populacional, como acontece em população muito pequena.

Os dois mais importantes princípios de uma amostragem são a casualidade e a comparabilidade. Os participantes devem ser escolhidos aleatoriamente, isto é, todos os elementos componentes do universo devem ter a mesma chance de serem selecionados e, as amostras devem ser comparáveis entre si, apesar de que, dificilmente, grupos populacionais sejam estritamente comparáveis. Em grupos humanos, são mais fáceis de controlar as variáveis físicas como cor, sexo, idade, estatura e peso; são mais difíceis de controlar as condições sócioeconômicas, culturais e psicológicas.

\section{PROBLEMÁTICA NA EXECUÇÃO DO TRABALHO DE CAMPO}

Problemas ambientais. A elevada temperatura nas áreas setentrionais do País traz problemas para a conservação de material perecível que precisa ser conservado em baixas temperaturas.

O excesso de chuvas, como também se verifica ao Norte, prejudica os deslocamentos na área e gera excesso de umidade que favorece o crescimento e disseminação de fungos. Os fungos constituem sério problema na contaminação de material biológico e para a conservação de material de laboratório nas áreas do trópico úmido. As precárias vias de acesso no campo, principalmente no período chuvoso, ocasionam graves problemas para a realização e progressão das tarefas.

Risco biológico. O pesquisador não pode desconhecer os riscos biológicos a que ele e toda a equipe estão sujeitos em conseqüência da manipulação ou da exposição a agentes patógenos e que poderão resultar em infecção e doença.

Existem uma grande quantidade e variedade de potenciais riscos biológicos nos ambientes naturais: infecção por ingestão de patógenos através de água ou de alimentos contaminados (parasitoses intestinais, gastroenterites, cólera); infecção por inalação (histoplasmose, criptococose, tuberculose); infecção por via percutânea, seja por inoculação (tétano, micoses profundas), seja por penetração (leptospirose, esquistossomose) ou através de picadas de vetores (arboviroses, malária, tripanosomíases, leishmanioses, filarioses, etc).

Ao pesquisador cabe delinear as funções do pessoal designado aos diferentes encargos, fazendo recomendações específicas quanto ao risco ao qual cada um estará exposto em suas atribuições, proporcionando-lhes os meios adequados de proteção, sem esquecer de providenciar, quando indicada, a imunização específica (v.g. aos que trabalham em área
$\mathrm{Na}$ definição dos casos de doenças de latência clínica, como a malária, ou com evidente potencial evolutivo, como a doença de Chagas, torna-se necessário para o estudo clínico-epidemiológico uma prévia determinação dos critérios diagnósticos. A caracterização da malária aguda será feita com base na presença de febre e de um patamar de parasitemia. Por outro lado, a caracterização das formas clínicas da doença de Chagas torna-se difícil pelo caráter evolutivo que permite a superposição de formas clínicas sem delimitação nítida entre si $^{9}$.

Duração do estudo. Inquéritos e estudos seccionais poderão ter um tempo limitado à permanência do surto que se quer avaliar ou ao tamanho da amostra em estudo. Estudos longitudinais de doenças de evolução lenta carecerão de uma duração de 5 a 10 anos. É claro que quanto maior a duração do estudo longitudinal, maior a chance de obtenção de respostas para um maior número de questões.

endêmica de febre amarela) ou a quimioprofilaxia (v.g. aos que estão em área de malária) e, instruindo-os sobre as medidas específicas e condutas a serem tomadas em caso de possível exposição ${ }^{15}$.

Dificuldades ligadas a aspectos culturais e hábitos da população. A condução e a manutenção da pesquisa de campo é sempre mais difícil do que a implantação, conseqüente a vários fatores inerentes à cultura e aos costumes da população rural.

A localização dos pacientes, principalmente quando são crianças, ou das famílias participantes, durante as visitas subseqüentes, pode determinar enormes dificuldades geradas pelas mais diversas situações: troca de nome das localidades ou logradouros; localidades conhecidas por denominações diferentes; existência de designação oficial e popular de um mesmo local; embaraço do camponês em determinar com precisão local e número da moradia; crianças que ora permanecem em casa de um ou de outro parente; residências temporárias por motivos de doença, de estudos ou de trabalho; e grande mobilidade da população no campo, especialmente em área de colonização recente.

As visitas planejadas poderão resultar infrutíferas se forem programadas sem respeito aos hábitos da população durante feriados e dias santos, ou para épocas em que os moradores estejam trabalhando em locais remotos, em caçadas ou em pescarias, como é comum acontecer na região amazônica; também, as crianças e adolescentes podem estar em período letivo, freqüentando escolas em localidades distantes. Por vezes, os pesquisadores são mal recebidos, identificados como agentes do governo para espionálos no direito à terra e à moradia, sobre renda e pagamentos de tributos, causando discordâncias às pesquisas de âmbito sócioeconômico. 
São freqüentes as cobranças de melhorias locais, tais como instalação de estradas, hospitais, postos de saúde, luz elétrica, escolas, meios de transporte, etc. como condições para continuidade de colaboração. Estas situações exigirão não apenas uma excelente comunicação do pesquisador com a comunidade e com os poderes públicos mas, também, pronta ação de educação sanitária no sentido de fazer compreender o bem maior da saúde, de modificar deturpações, hábitos e erros da ignorância, tarefa que exige prévio e adequado treinamento dos pesquisadores de campo ${ }^{14}$.

Apoio logístico. Um meio de transporte motorizado é essencial para se vencer as longas e difíceis distâncias na área rural. A camionete com tração nas quatro rodas e cabine dupla tem se mostrado o veículo ideal, permitindo acomodação da equipe e do material de trabalho. É importante o zêlo na conservação da viatura e o cuidado de que não seja desviada para outros fins porque, no campo, torna-se ás vezes tão imprescindível quanto o próprio material técnico-científico para se atingir as metas propostas. A quantidade de combustível necessária ao cumprimento das missões, deverá ser prevista adequadamente, inclusive portando-se uma quantidade extra de reserva, em recipientes seguros e apropriados. Na região amazônica, com freqüência se torna necessário a aquisição de um barco a motor e, em determinadas áreas rurais do país, onde as estradas ainda não existem, ou são raras e péssimas, um animal de montaria poderá ser indispensável para alcançar muitas habitações de difícil acesso.

A quantidade do material de consumo a ser utilizado, carece ser antecipadamente estipulada e estocada. Mais difícil é o suprimento de energia elétrica para fazer funcionar microscópios, centrífugas, refrigeradores, etc. Por isso, no campo, é mais conveniente o microscópio de luz natural e, para a conservação de material biológico, a garrafa de nitrogênio líquido, em vez de freezers e geladeiras elétricas.

Problemas comportamentais. O investigador de campo deverá reunir qualidades humanas de pessoa sincera, movida pela solidariedade e por um forte sentimento de justiça social, capaz de se preocupar honestamente com os mais necessitados e de com eles se identificar, se quiser ter acesso garantido e confiável às informações e à colaboração da comunidade. Ele deverá ter uma atitude de serena humildade e de respeito pelos menos favorecidos, saber ouvir cuidadosamente, informar corretamente e consultar ativamente aqueles a quem se dispõe a investigar e que constituem, em última análise, o objetivo maior de sua ação profissional.

Ante a gente humilde e de hábitos regrados que habita o campo, ao pesquisador cumprirá adotar um comportamento moral e ético compatível, sublimar seus ímpetos de impaciência e de ira, suprimir sua inclinação para os vícios, para o alcoolismo, para a toxicomania, para a lascívia carnal. A população estará sempre vigilante à compostura daquele a quem confia e tem como paradigma de correção de conduta.

O investigador de campo evitará o envolvimento com questões partidárias políticas ou religiosas, lembrandose que irá estudar pessoas independentemente do credo e do pensamento político. Atentará que as carências materiais inerentes ao campo tornam as pessoas mais dependentes umas das outras e impõem a solidariedade como regra geral de sobrevivência.

O pesquisador no campo respeitará a cultura, a tradição, os hábitos e a inteligência da população a que pretende estudar. Certamente, irá defrontar com problemas médicos ligados a costumes locais, tais como a automedicação, a medicina popular, as prescrições de práticos e de farmacêuticos, etc. Essas questões deverão ser encaradas com grande flexibilidade diante da realidade que enfrenta o campesino, orientando com paciência e coibindo os excessos e os erros grosseiros prejudiciais à saúde do indivíduo. Pesquisar no campo exige uma gama de conhecimentos, de habilidades e de atitudes que não devem ser desprezadas. O hábito de escrever um diário, registrando todas as observações que julgar interessantes, revelar-seá mais cedo ou mais tarde de preciosa utilidade ao pesquisador aberto a todas as informações relativas ao ambiente de sua investigação.

O pesquisador assumirá sempre uma atitude humanitária diante das atribulações que afligem as populações pobres porém, deve evitar tanto o autoritarismo quanto o paternalismo. Assim, a atitude excessivamente protecionista poderá induzir a uma dependência viciosa, claramente prejudicial ao pesquisador que nem sempre terá recursos disponíveis para resolver todos os problemas. Por outro lado, o clínico que vai ao campo para pesquisar deve estar consciente de ser, antes de tudo médico, e que muitas vezes poderá ser o único facultativo ao alcance da população. Desta forma, não poderá se fechar na torre de marfim de sua pesquisa mas, deverá estar disponível para exercer a assistência, sempre que necessário. A presteza médica será muito importante para a valorização do pesquisador e da pesquisa; ao contrário, a inércia e a indiferença ante o sofrimento do povo, certamente suscitarão a falta de colaboração e as desistências do estudo.

Enfim, o humanitarismo, a capacidade de comunicação, a dedicação, o interesse e a experiência prática valerão no trabalho de campo muito mais do que muitos livros e diplomas.

\section{CONSIDERAÇÕES SOBRE AS PERSPECTIVAS DAS PESQUISAS DE CAMPO NO BRASIL}

As pesquisas de campo no Brasil deverão evoluir para uma abrangência regional e mesmo para uma integração a nível nacional, deixando de ser experiências isoladas e ocasionais, para que enfim se possa conhecer o real e completo panorama de nossas endemias. 
O progresso do país urge caminhar para o patrocínio nacional da investigação de nossas doenças com pessoal e recursos próprios, acabando ou diminuindo a dependência externa, econômica ou científica.

O trabalho de campo precisa atrair cada vez mais a participação ativa da comunidade, conscientizando-a a abandonar a atitude puramente passiva na resolução dos seus problemas.

As pesquisas de campo deverão voltar-se a ter uma maior preocupação com a saúde e menos com a doença. A investigação no âmbito domiciliar, atentando para todos os elementos ambientais relacionados ao indivíduo deverá ser mais incrementada do que a pesquisa em postos médicos.

Às escolas médicas importa incentivar com mais ênfase a formação de novos pesquisadores de campo, estimulando a busca das soluções para os graves problemas que representam as doenças tropicais para a saúde da grande massa de concidadãos que habitam os mais distantes rincões do país.

\section{REFERÊNCIAS BIBLIOGRÁFICAS}

1. Andrade ZA, Santos JB, Prata A, Dourado H. Histopatologia da Hepatite de Lábrea. Revista da Sociedade Brasileira de Medicina Tropical 16:31-40, 1983.

2. Araújo MOG. Morfologia placentária associada à infecção malárica da gestante: microscopia óptica, eletrônica e estudo imuno-histológico. Revista da Sociedade Brasileira de Medicina Tropical 26:129-130, 1993.

3. Auad A. Pênfigo foliáceo sul-americano no Estado de Goiás. Revista de Patologia Tropical 1: 293-346, 1972.

4. Batista-Silva E, Alecrim WD, Costa MRF, Melo YFC, Arcanjo ARL, Alecrim MGC. Estudo soroepidemiológico de malária humana em área urbana e comunidade rural do município de Novo Airão, Estado do Amazonas. Revista da Sociedade Brasileira de Medicina Tropical 32(supl I):272-273, 1999.

5. Bermejo A, Veeken $\mathrm{H}$. Insecticide-impregnated bed nets for malaria control: a review of the field trials. Bulletin of the World Health Organization 70:293-296, 1992.

6. Bina JC, Prata A. Regressão da hepatoesplenomegalia pelo tratamento específico da esquistossomose. Revista da Sociedade Brasileira de Medicina Tropical 16:213-218, 1983.

7. Castro CNC. Influência da parasitemia no quadro clínico da Doença de Chagas. Revista de Patologia Tropical 9:73-136, 1980.

8. Chagas C. Nova tripanozomiaze humana. Estudos sobre a morfologia e o ciclo evolutivo do Schizotrypanum cruzi n. gen., n. sp., agente etiológico de nova entidade mórbida do homem. Memórias do Instituto Oswaldo Cruz 1(supl II):1-62, 1909.

9. Conselho Nacional de Pesquisas. Epidemiologia da Doença de Chagas. Objetivos e Metodologia dos Estudos Longitudinais. Relatório Técnico n 1, 1974.

10. Del Guercio VMF, Rocha MMM, Melles HHB, Lima VCL, Pignatti MG. Febre Maculosa no município de Pedreira, SP, Brasil. Inquérito sorológico. Revista da Sociedade Brasileira de Medicina Tropical 30:47-52, 1997

11. Dias JCP. Problemas e possibilidades de participação comunitária no controle das grandes endemias do Brasil. Cadernos de Saúde Pública 14(supl II):19-37, 1998

12. Dias RB. "Eu? Eu estou aí, compondo o mundo", uma experiência de controle de endemia, pesquisa e participação popular vivida em Cansanção, Minas Gerais, Brasil. Cadernos de Saúde Pública 14(supl II):149-157, 1998.

13. Farrell B. Efficient management of randomised controlled trials: nature or nurture. British Medical Journal 317:1236-1239, 1998.

14. Goyea HS. General and specific problems of field work in child health care: Benin City. Tropical Pediatrics and Environmental Child Health 24:167-170, 1978.
15. Llanes RF, Abreu CF, Gonzalez OF. Riesgo biologico asociado con trabajos de campo: informe de 2 casos de histoplasmosis. Revista Cubana de Medicina Tropical 39:61-67, 1987.

16. Macêdo VOM. Forma indeterminada da Doença de Chagas. Jornal Brasileiro de Medicina 38:34-40, 1980.

17. Ministério da Saúde. Diretrizes e normas regulamentadoras de pesquisa envolvendo seres humanos. Secretaria de Assistência à Saúde. Conselho Nacional de Saúde. Programa Nacional de Doenças Transmissíveis/AIDS, 1997.

18. Moraes MAP, Fraiha H, Chaves GM. Oncocercose no Brasil. Boletin de la Oficina Sanitaria Panamericana 76:48-54, 1974.

19. Oliveira MHP, Romanelli G. Os efeitos da hanseníase em homens e mulheres: um estudo do gênero. Cadernos de Saúde Pública 14:51-60, 1998.

20. Oliveira RM, Andrade ALSS, Martelli CMT. Considerações Metodológicas e Operacionais na Condução de Ensaios Clínicos em áreas Rurais Endêmicas para Doença de Chagas. Revista de Patologia Tropical 29:45-60, 2000.

21. Organización Mundial de la Salud. Serie de Informes Técnicos. $n^{\circ} 850$. Pautas para la buena práctica clínica (BPC) en ensayos con productos farmacéuticos. Ginebra, p. 114-156, 1995.

22. Pessoa S. A Luta contra as Endemias Parasitárias na Nova China In: Pessoa S (ed) Ensaios Médicos Sociais, $1^{a}$ edição, Guanabara Koogan, Rio de Janeiro, p. 267-284, 1960.

23. Pessoa S. Medicina Rural e Socialização da Medicina. In: Pessoa $S$ (ed) Ensaios Médicos Sociais, $1^{\text {a }}$ edição, Guanabara Koogan, Rio de Janeiro, p. 181-193, 1960

24. Pessoa S. A Pesquisa em Saúde Pública. In: Ensaios Médicos Sociais, $3^{a}$ edição, Guanabara Koogan, Rio de Janeiro, p. 285303, 1983.

25. Pinheiro FP, Rosa APAT, Moraes MAP. An epidemic of yellow fever in Central Brazil, 1972-1973. The American Journal of Tropical Medicine and Hygiene 30:204-211, 1981.

26. Prata A, Urdaneta M, McGreevy PB, Tada MS. Infrequency of asymptomatic malaria in an endemic area in Amazonas, Brazil. Revista da Sociedade Brasileira de Medicina Tropical 21:51-54, 1988.

27. Santos JB. Inquérito clínico-epidemiológico no surto de Febre Amarela de 1973, em 19 municípios do Brasil Central. In: Resumos do XIII Congresso da Sociedade Brasileira de Medicina Tropical, Brasília p. 300, 1977.

28. Santos JB. Febre Negra na Região de Lábrea, Amazonas. Estudo Clínico, Epidemiológico e Histopatológico. Tese de Mestrado, Universidade de Brasília, Brasília, DF, 1978. 
29. Santos JB, Prata A. Tratamento de 75 pacientes portadores de malária pelo $P$. falciparum, em Porto Velho (RO), com mefloquina. Revista da Sociedade Brasileira de Medicina Tropical 21:181185, 1988.

30. Santos JB, Santos F, Marsden P, Tosta CE, Andrade ALSS, Macêdo V. Ação dos mosquiteiros impregnados com deltametrina sobre a morbidade da malária em uma área da Amazônia Brasileira. Revista da Sociedade Brasileira de Medicina Tropical 31:1-9, 1998.
31. Silva IG. Distribuição, Densidade e Domiciliação das Espécies Secundárias e o Risco da Transmissão da Doença de Chagas no Estado de Goiás. Revista da Sociedade Brasileira de Medicina Tropical 26(supl II):40-41, 1993.

32. Urdaneta M, Prata A, Struchiner CJ, Tosta CE, Tauil P, Boulos M. Safety evaluation of SPf66 Malaria Vaccine in Brazil. Revista da Sociedade Brasileira de Medicina Tropical 29:497-501, 1996. 